\title{
Refining the Patient Navigation Role in a Colorectal Cancer Screening Program: Results From an Intervention Study
}

\author{
Elizabeth A. Rohan, PhD, MSWa; Beth Slotman, MS ; Amy DeGroff, PhD, MPHª Kerry Grace Morrissey, MPH' \\ Jennifer Murillo, BAc ${ }^{c}$; and Paul Schroy, MD, $\mathrm{MPH}^{\mathrm{c}}$
}

\begin{abstract}
Background: Oncology patient navigators help individuals overcome barriers to increase access to cancer screening, diagnosis, and timely treatment. This study, part of a randomized intervention trial investigating the efficacy of patient navigation in increasing colonoscopy completion, examined navigators' activities to ameliorate barriers to colonoscopy screening in a medically disadvantaged population. Methods: This study was conducted from 2012 through 2014 at Boston Medical Center. We analyzed navigator service delivery and survey data collected on 420 participants who were navigated for colonoscopy screening after randomization to this intervention. Key variables under investigation included barriers to colonoscopy, activities navigators undertook to reduce barriers, time navigators spent on each activity and per contact, and patient satisfaction with navigation services. Descriptive analysis assessed how navigators spent their time and examined what aspects of patient navigation were most valued by patients. Results: Navigators spent the most time assessing patient barriers/needs; facilitating appointment scheduling; reminding patients of appointments; educating patients about colorectal cancer, the importance of screening, and the colonoscopy preparation and procedures; and arranging transportation. Navigators spent an average of 44 minutes per patient. Patients valued the navigators, especially for providing emotional/peer support and explaining screening procedures and bowel preparation clearly. Conclusions: Our findings help clarify the role of the navigator in colonoscopy screening within a medically disadvantaged community. These findings may help further refine the navigator role in cancer screening and treatment programs as facilities strive to effectively and efficiently integrate navigation into their services.
\end{abstract}

J Natl Compr Canc Netw 2016;14(11):1371-1378

\section{NCCN: Continuing Education}

\section{Accreditation Statement}

This activity has been designed to meet the educational needs of physicians and nurses involved in the management of patients with cancer. There is no fee for this article. No commercial support was received for this article. The National Comprehensive Cancer Network (NCCN) is accredited by the ACCME to provide continuing medical education for physicians.

NCCN designates this journal-based CME activity for a maximum of 1.0 AMA PRA Category 1 Credit ${ }^{\mathrm{TM}}$. Physicians should claim only the credit commensurate with the extent of their participation in the activity.

From aDivision of Cancer Prevention and Control, Centers for Disease Control and Prevention, Atlanta, Georgia; bWestat, Rockville, Maryland; and 'Boston Medical Center, Department of Gastroenterology, Boston, Massachusetts.

Submitted May 10, 2016; accepted for publication July 13, 2016.

The authors have disclosed that they have no financial interests, arrangements, affiliations, or commercial interests with the manufacturers of any products discussed in this article or their competitors. The findings and conclusions in this manuscript are those of the authors and do not necessarily represent the official position of the Centers for Disease Control and Prevention.

Author Contributions: Study principal investigators: Rohan, DeGroff, and Schroy. Study project director: Morrissey. Study project manager: Slotman. Study project team: Murillo. Manuscript conceptualization: Rohan. Data collection: Slotman (management), Murillo, and Schroy (oversight). Manuscript preparation and data analysis: Rohan and Slotman. Manuscript editing: Rohan, Slotman, DeGroff, Morrissey, Murillo, and Schroy.

Correspondence: Elizabeth A. Rohan, PhD, MSW, Centers for Disease Control and Prevention, Division of Cancer Prevention and Control, 4770 Buford
NCCN is accredited as a provider of continuing nursing education by the American Nurses Credentialing Center's Commission on Accreditation.

NCCN designates the education activity for a maximum of 1.0 contact hour. Accreditation as a provider refers to recognition of educational activities only; accredited status does not imply endorsement by NCCN or ANCC of any commercial products discussed/displayed in conjunction with the educational activity. Kristina M. Gregory, RN, MSN, OCN, is our nurse planner for this educational activity.

All clinicians completing this activity will be issued a certificate of participation. To participate in this journal CE activity: 1) review the

Highway, NE, Chamblee Building 107, MS F76, Atlanta, GA 30341-3717. E-mail: erohan@cdc.gov

\section{EDITOR}

Kerrin M. Green, MA, Assistant Managing Editor, JNCCN—Journal of the National Comprehensive Cancer Network

Ms. Green has disclosed that she has no relevant financial relationships.

\section{CE AUTHORS}

Deborah J. Moonan, RN, BSN, Director, Continuing Education, has disclosed that she has no relevant financial relationships.

Ann Gianola, MA, Manager, Continuing Education Accreditation \& Program Operations, has disclosed that she has no relevant financial relationships. Kristina M. Gregory, RN, MSN, OCN, Vice President, Clinical Information Operations, has disclosed that she has no relevant financial relationships. Rashmi Kumar, PhD, Senior Manager, Clinical Content, has disclosed that she has no relevant financial relationships.

Ndiya Ogba, PhD, Oncology Scientist/Medical Writer, has disclosed that she has no relevant financial relationships. 
learning objectives and author disclosures; 2) study the education content; 3 ) take the posttest with a $66 \%$ minimum passing score and complete the evaluation at http://education.nccn.org/ node/79763; and 4) view/print certificate.

Release date: November 1, 2016; Expiration date: November 1, 2017

\section{Learning Objectives}

Upon completion of this activity, participants will be able to:

- Examine the oncology PN role in alleviating barriers to colonoscopy screening in a medically disadvantaged population

- Ascertain PN intervention activities during colonoscopy screening most valued by patients that potentially improve patient outcomes

\section{Background}

Oncology patient navigation $(\mathrm{PN})$ is recognized as an important component of cancer care and, as of 2015, all Commission on Cancer (CoC)-accredited programs are required to provide $\mathrm{PN}$ services. ${ }^{1}$ Oncology PN, pioneered by Dr. Harold Freeman in $1990,{ }^{2}$ is a process that provides "individualized assistance to patients, families, and caregivers to help overcome healthcare system barriers and facilitate timely access to quality health and psychosocial care from prediagnosis through all phases of the cancer experience." ${ }^{3}$ Prediagnosis includes screening, which detects disease early when treatment is the most effective. ${ }^{4}$ Disparities in cancer screening persist and are based on race, ethnicity, and healthcare access and use, among other factors. ${ }^{5-8}$ Studies have shown the effectiveness of $\mathrm{PN}$ in increasing patient completion of cancer screening and reducing disparities among the medically underserved..$^{9-17}$

Generally, patient navigators (herein referred to as "navigators") are either nonclinical members of the community or healthcare professionals (usually nurses or social workers). ${ }^{4,18,19}$ Many PN programs use navigators who are members of the population they serve, thus they are able to meaningfully address norms related to health beliefs, trust in the medical system, and language barriers. ${ }^{20-24}$ Navigators help patients overcome practical barriers to cancer screening, diagnosis, and treatment; provide culturally appropriate patient education; offer peer counseling; and provide linkages to financial and community resources. ${ }^{2,21,25-29}$ These activities align with the evidence-based strategies to increase early detection through screening as recommended by the Community Preventive Services Task Force, including offering client reminders and outreach, providing one-on-one education, and reducing structural (ie, practical) barriers. ${ }^{30}$

As PN programs in cancer screening are increasingly being implemented in healthcare settings, it is crucial to understand navigator activities and to ascertain the value of $\mathrm{PN}$ interventions to patients. Such information will yield greater understanding of the navigator activities that are most critical to improved outcomes and enhance effective use of navigators within healthcare teams. Although some studies have systematically examined PN activities in cancer treatment settings, ${ }^{23,26,31,32}$ few have been conducted in cancer screening. 33,34 Additionally, few PN studies include patient satisfaction measures in their design, ${ }^{11,35-37}$ and only one ${ }^{35}$ specifically examined the aspects of $\mathrm{PN}$ intervention that were valued by patients.

Our study was conducted as part of a larger examination of the efficacy of PN in increasing colorectal cancer (CRC) screening via colonoscopy in a medically disadvantaged population. This analysis was performed to characterize the activities of navigators, including time spent per activity and per patient, using the data collected by the navigators. Additionally, this study examined the extent to which patients valued and were satisfied with the PN intervention, including which aspects of the intervention patients considered most useful.

\section{Methods}

Data were obtained from the intervention arm of the Study of Patient Navigation for Colonoscopy, a randomized intervention study exploring the use of $\mathrm{PN}$ to increase screening colonoscopy in a medically disadvantaged population (E.A.R, unpublished data, 2016). The study was conducted at Boston Medical Center (BMC) and approved by Institutional Review Boards of the Centers for Disease Control and Prevention (CDC), BMC, and Westat.

\section{Population}

We recruited participants aged 50 to 75 years who were referred for screening colonoscopy from October 2012 to December 2014 at BMC's Section of General Internal Medicine, BMC's Family Medicine Department, and the East Boston Neighborhood Health Center. BMC is the largest 
safety-net hospital in New England. Participants were prescreened based on eligibility criteria and were then recruited via telephone; those not reached by telephone were mailed an invitation letter. All participants had either private or public insurance that covered screening colonoscopy. Participants assigned to the control arm $(n=423)$ received usual care, typically consisting of 1 informational call and 1 appointment reminder call.

\section{Intervention}

The intervention was conducted by 2 nonclinical navigators. Both navigators were recruited by BMC, were bilingual (English/Spanish), had experience in health care or community health settings, and were familiar with the local community. One navigator had significant PN experience and had previously received additional training in motivational interviewing from Boston University School of Medicine; the other navigator was trained for this study by the Harold P. Freeman Patient Navigation Institute and was mentored by the senior navigator. The junior navigator had a bachelor's degree and the senior navigator was working toward earning a bachelor's degree. Navigators were employed by BMC to work with study participants 20 hours per week for this study. A full-time research coordinator led participant recruitment through November 2013, after which the navigators served as parttime recruiters. Participants were not recruited and serviced by the same navigator (ie, the senior navigator provided navigation only to those recruited by the junior navigator and vice versa). Navigators worked with patients to identify, reduce, and eliminate personal, cultural, structural, and healthcare system barriers to screening colonoscopy and to support completion of the procedure.

Navigators first conducted an assessment of participants to identify relevant barriers to colonoscopy screening. Based on the assessment, they created a plan to facilitate the screening process. Navigators worked with participants primarily via phone, but also conducted some activities in person and by mail. Navigators used the PN Colonoscopy Tracking Form (a database in the medical records system) to track participants through the screening process and to document service completion for each contact (see supplemental eAppendix 1, available with this article at JNCCN.org).
Consistent with the intervention design, some activities were common among all navigated patients, such as assessment of barriers, patient tracking and follow-up, education about CRC screening and clearing the bowels in preparation for colonoscopy (hereafter referred to as bowel prep), and appointment reminders. Other activities were more individualized, such as addressing patient-specific barriers to colonoscopy screening. The PN intervention ended (1) when a patient completed their colonoscopy, received the results, and the referring primary care provider received the endoscopy report; or (2) if a patient had not undergone a colonoscopy within 6 months after study enrollment.

\section{Data Collection}

Data for this analysis were obtained from participant baseline and follow-up questionnaires and the PN Colonoscopy Tracking Form. Research coordinators conducted the 15-minute participant baseline survey primarily via telephone; this information was used for evaluation of the intervention and not shared with navigators. The baseline questionnaire assessed participant demographics and barriers to screening. All participants received a $\$ 25$ gift card for completing the baseline survey. As soon as possible after colonoscopy was completed or if the participant was deemed nonadherent after 6 months, participants were called by a professional telephone interviewer (from Westat), who conducted a 10-minute followup survey. This survey included some of the same questions as the baseline questionnaire, but also included questions about patient satisfaction with navigation, including identifying which $\mathrm{PN}$ activities patients found most helpful. After completion of the follow-up survey, participants received another $\$ 25$ gift card.

Navigators documented each patient contact (or activities conducted on behalf of the patient) in the electronic PN Colonoscopy Tracking Form, noting the type of activity (eg, phone, in person, mail, e-mail, no patient contact needed, flag provider, colonoscopy notes), patient barriers assessed (eg, lack of education about colonoscopy, language barriers, lack of transportation, securing an escort for the appointment), activities taken to address identified barriers, time spent on each activity, and overall time spent during that contact. All time fields used 
Rohan et al

15-minute increments. Data entry occurred in real time, while the PN was speaking with the patient, or immediately on completion of the phone call.

\section{Data Analysis}

This analysis discusses the findings on the 420 navigated patients. Although the study assigned 431 patients to receive the intervention, 11 were not included in the analysis ( 5 could not be reached and 6 were excluded because their spoken language was

\section{Table 1. Demographics of Navigated Patients}

\begin{tabular}{|c|c|c|}
\hline \multicolumn{2}{|c|}{ Characteristic } & N (\%) \\
\hline \multicolumn{2}{|c|}{ Total navigated patients } & 420 \\
\hline \multicolumn{3}{|l|}{ Age, y } \\
\hline & $50-54$ & $222(52.9)$ \\
\hline & $55-64$ & $142(33.8)$ \\
\hline & $65-74$ & $55(13.1)$ \\
\hline & DK, refused, not ascertained & $1(<1.0)$ \\
\hline \multicolumn{3}{|l|}{ Sex } \\
\hline & Male & $187(44.5)$ \\
\hline & Female & $233(55.5)$ \\
\hline \multicolumn{3}{|c|}{ Race/Ethnicity } \\
\hline & Hispanic & $164(39.0)$ \\
\hline & Non-Hispanic black & $170(40.5)$ \\
\hline & Non-Hispanic white & $64(15.2)$ \\
\hline & Other & $21(5.0)$ \\
\hline & DK, refused, not ascertained & $1(<1.0)$ \\
\hline \multicolumn{3}{|c|}{ Language spoken at home } \\
\hline & English & $234(55.7)$ \\
\hline & Other than English & $185(55.0)$ \\
\hline & DK, refused, not ascertained & $1(<1.0)$ \\
\hline \multicolumn{3}{|c|}{ Income (US dollars) } \\
\hline & $\$ 0-\$ 19,999$ & $244(58.1)$ \\
\hline & $\$ 20,000-\$ 34,999$ & $63(15.0)$ \\
\hline & $\$ 35,000-\$ 49,999$ & $30(7.1)$ \\
\hline & $\$ 50,000-\$ 74,999$ & $15(3.6)$ \\
\hline & $\geq \$ 75,000$ & $23(5.5)$ \\
\hline & DK, refused, not ascertained & $45(10.7)$ \\
\hline \multicolumn{3}{|c|}{ Health insurance ${ }^{a}$} \\
\hline & Private & $87(20.7)$ \\
\hline & Public & $373(88.8)$ \\
\hline & DK, refused, not ascertained & $3(<1.0)$ \\
\hline
\end{tabular}

Abbreviation: DK, don't know.

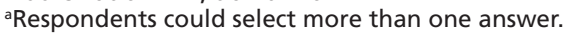

neither English nor Spanish). Summary statistics were generated for demographic variables (age, sex, race/ethnicity, language spoken at home, and income). We calculated frequency distributions for barriers reported in the baseline questionnaire, types of activities performed by the PN, and patient satisfaction questions. We calculated the average time PNs spent per patient and per activity for each patient by using the midpoint of each 15-minute time increment, omitting extreme outliers to more accurately represent mean time navigators spent with the patients. We conducted a content analysis on open-ended responses to questions about PN services that patients deemed were most helpful. Responses were coded by the second author (B.S.) and this coding was reviewed by the first (E.A.R.). We resolved differences through consensus, subsequently grouped codes into themes (education, emotional support, and practical support), and calculated the frequencies of responses for each code. All other analyses were performed with SAS version 9.3 (SAS Institute Inc., Cary, NC).

\section{Results}

Demographic data for the 420 patients who received navigation services are summarized in Table 1 . Approximately half of the patients were aged 50 to 54 years $(52.9 \%)$ and a similar proportion were female $(55.5 \%)$. Most patients were either nonHispanic black $(40.5 \%)$ or Hispanic $(39.0 \%)$, and slightly more than half spoke English as their primary language $(55.7 \%)$. More than half of the patients

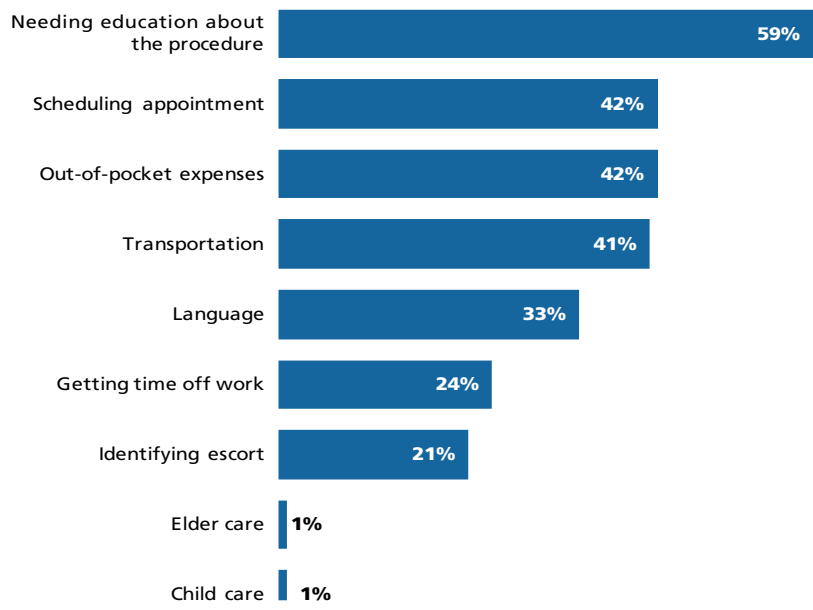

Figure 1. Barriers reported at baseline by patients randomized to receive navigation ( $\mathrm{N}=420$ ). 
Patient Navigation in a CRC Screening Program

\begin{tabular}{|lc|}
\hline \multicolumn{2}{|c|}{$\begin{array}{l}\text { Table 2. Average Time Spent Per Patient } \\
\text { Across All Activities }\end{array}$} \\
\hline \multicolumn{1}{|c|}{ Minutes } \\
\hline $\mathrm{N}^{\mathrm{a}}$ & 404 \\
\hline Mean (SD) & $43.7(31.3)$ \\
\hline Minimum & 7 \\
\hline 25th percentile & 21 \\
\hline 50th percentile & 35 \\
\hline 75th percentile & 56 \\
\hline
\end{tabular}

aParticipants with 0 or $>180$ minutes were not included.

had incomes of less than $\$ 20,000$ (58.1\%); most patients reported incomes under $\$ 50,000(80.2 \%)$. Most patients were publicly insured (88.8\%).

At baseline, $98 \%$ of patients reported at least 1 barrier (data not shown); $57 \%$ of patients reported between 1 and 3 barriers, and $41 \%$ reported 4 or more barriers (data not shown). Patients faced challenges at multiple levels, including individual and interpersonal, cultural, environmental/structural, and healthcare system (Figure 1). The most commonly reported barrier was needing education about the colonoscopy procedure (59\%), followed by scheduling the appointment (42\%), out-of-pocket expenses related to the procedure (42\%), and transportation (41\%). One-third of patients (33\%) anticipated the need for language translation. Slightly less than a quarter of patients reported time off work or identifying an escort home (required after sedation) as barriers to undergoing colonoscopy (24\% and 21\%, respectively). Navigators identified additional barriers through their assessment and over the course of navigation.

Across all activities, navigators spent an average of 44 minutes per patient (Table 2), and $75 \%$ received less than 1 hour of navigation services. Figure 2 illustrates the percentage of patients receiving each navigator activity and the average number of minutes spent on that activity per patient for the activity reported. Aside from assessment and planning, navigator activities corresponded closely to patient-reported barriers (as reported in Figure 1). Navigators spent more time overall on the most frequently reported activities. On average, navigators spent the greatest amount of time conducting assessment and planning (mean, 27.2 minutes per patient), which was also their most

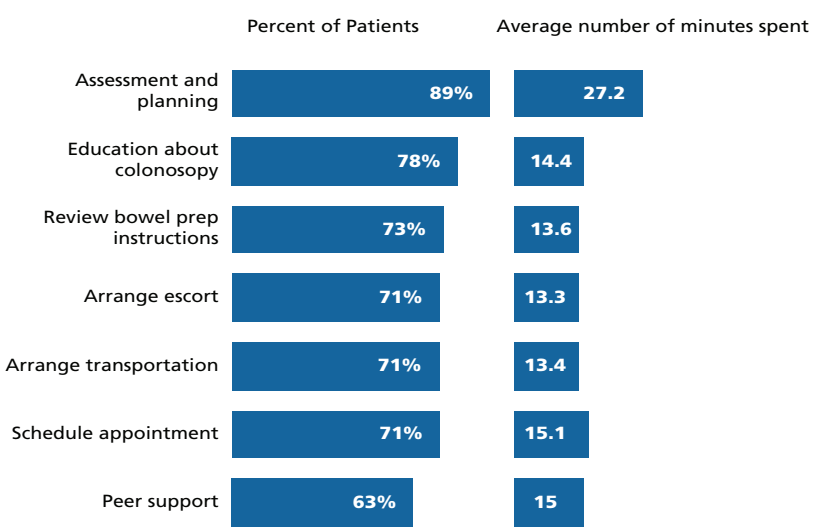

Figure 2. Percentage of patients for which patient navigators reported activity and average time spent on activity per patient $(n=413)$.

frequently reported activity (89\%). Other frequently reported navigator activities included delivering education about colonoscopy (78\%; 14.4 minutes), reviewing bowel prep instructions (73\%; 13.6 minutes), scheduling or rescheduling colonoscopy appointments (71\%; 15.1 minutes), arranging transportation (71\%; 13.4 minutes), arranging for an escort (71\%; 13.3 minutes), and providing peer support $(63 \% ; 15.0$ minutes $)$.

Patients completing the follow-up questionnaire $(\mathrm{n}=287)$ were highly satisfied with the PN services (Figure 3). Nearly all (96\%) would recommend PN services to others, valued working with their navigator (95\%), and rated their experience good, very good, or excellent (95\%).

Table 3 summarizes navigation services patients identified as most helpful in the follow-up survey. Their responses largely related to education, emotional support, and practical support services. Nearly half of the patients valued the explanation of the colonoscopy procedure and bowel prep procedures $(47.1 \%$ and $46.7 \%$, respectively), followed by providing encouragement/social support $(40.5 \%)$. Several patients reported their fear of the colonoscopy and that the navigator was able to alleviate their fears and anxiety, thereby convincing them to complete their colonoscopy. Many patients reported that they were thankful to have someone to listen to their concerns and answer questions. Education about the importance of completing the colonoscopy $(12.8 \%)$ was also identified as helpful, as were arrangement of transportation or escort after the procedure $(7.5 \%)$, appointment scheduling/ rescheduling $(7.0 \%)$, and language concordance between patient and navigator $(3.1 \%)$. 
Rohan et al

\begin{tabular}{|c|c|c|c|c|}
\hline \multirow{3}{*}{$\begin{array}{l}\text { Recommend patient } \\
\text { navigators to others } \\
(n=237)\end{array}$} & Strongly agree & Agree & \multicolumn{2}{|c|}{ Disagree } \\
\hline & $40 \%$ & $56 \%$ & & $4 \%$ \\
\hline & Strongly agree & Agree & & isagree \\
\hline \multirow[t]{2}{*}{$\begin{array}{l}\text { Value working with } \\
\text { patient navigators } \\
(\mathrm{n}=232)\end{array}$} & $31 \%$ & $64 \%$ & & $5 \%$ \\
\hline & Excellen & Very good & Good & Fair/Poor \\
\hline $\begin{array}{l}\text { Rate experience with } \\
\text { patient navigators } \\
(\mathrm{n}=234)\end{array}$ & $58 \%$ & $23 \%$ & $14 \%$ & $5 \%$ \\
\hline
\end{tabular}

Figure 3. Patients' satisfaction with patient navigators.

\section{Discussion}

These study data provide insight into how the PN role can be further refined. In our study, PN activities corresponded closely to patient-reported barriers, although a lower percentage of patients anticipated having each barrier. Our findings show that navigators in our study spent the most time assessing needs/planning, educating participants about the procedure, reviewing bowel prep instructions, arranging escorts and transportation, scheduling appointments, and providing peer support. Some activities (eg, arranging escorts and reviewing bowel prep) are specific to colonoscopy, but overall, these activities correspond with findings from other examinations of PN activities in screening 33,34 and treatment. ${ }^{23,31,32}$ In our study, despite patients' anticipating needing assistance with out-of-pocket expenses for colonoscopy, navigators did not need to spend time addressing these concerns as other studies have reported, ${ }^{23}$ because all screening colonoscopies are covered by health insurance in Massachusetts..$^{38}$ Given the recent increase of PN programs in healthcare settings, it is necessary to better understand the activities navigators conduct, including how much time they spend engaging in these activities.

Navigators in our study spent an average of 44 minutes per patient, which is less than other studies have reported; one study in cancer screening found that navigators spent an average of 107 minutes with each patient. ${ }^{14}$ Navigators in that study helped patients decide between colonoscopy and fecal occult blood test, which could account for the longer time reported. Similarly, a study of navigators in cancer treatment reported that navigators spent 2.5 hours per patient. ${ }^{23}$ This difference is not surprising, because it is expected that patient navigators working in a cancer treatment setting versus a cancer screening setting would work with patients over a longer period of time and address more complicated concerns.

Most patients in our study are from disadvantaged socioeconomic backgrounds. This is notable because disparities in healthcare access and treatment persist for those who are economically disadvantaged and/ or members of racial and ethnic minority groups. ${ }^{5-8,39}$ Interestingly, a recent multicenter, randomized control trial found that PN intervention decreased

\section{Table 3. Patient Navigation Services Patients Found Most Helpful $(n=227)$}

\begin{tabular}{|c|c|c|c|}
\hline \multicolumn{2}{|c|}{ Type of Support } & N (\%) & Illustrative Quote \\
\hline \multicolumn{4}{|l|}{ Education } \\
\hline & Explanation of colonoscopy procedure & $107(47.1)$ & $\begin{array}{l}\text { "They explained everything and followed up with any } \\
\text { questions that I had." }\end{array}$ \\
\hline & Bowel preparation & $106(46.7)$ & $\begin{array}{l}\text { "[The navigator] made sure that I was clear when to } \\
\text { start taking medication, how to mix, and when to mix } \\
\text { everything...made sure I did not eat." }\end{array}$ \\
\hline & Importance of procedure & $29(12.8)$ & $\begin{array}{l}\text { "[The navigator] explained...the reason for having the } \\
\text { procedure done and risks if you don't get it done." }\end{array}$ \\
\hline \multicolumn{4}{|c|}{ Emotional support } \\
\hline & Encouragement & $92(40.5)$ & "[The navigator] never gave up on me." \\
\hline \multicolumn{4}{|c|}{ Practical support } \\
\hline & Transportation/Escort & $17(7.5)$ & $\begin{array}{l}\text { "Kept in contact with me; made sure I had a ride to and } \\
\text { from." }\end{array}$ \\
\hline & Appointment scheduling & $16(7.0)$ & $\begin{array}{l}\text { "I missed my appointment and [the navigator] gave me a } \\
\text { call back to reschedule." }\end{array}$ \\
\hline & Language concordance & $7(3.1)$ & "Explained everything in detail in Spanish." \\
\hline
\end{tabular}


Patient Navigation in a CRC Screening Program

the time from abnormal screening result to diagnostic resolution, but only after a 90-day lag time. This finding led the authors to conclude that PN may be most effective for participants who are in the most need, such as those at higher risk of being lost to follow-up..$^{40}$

Finally, our study found that patients were highly satisfied with the PN intervention and most valued the navigators for providing emotional support and education. This builds on conclusions drawn from qualitative studies of navigators in cancer care, which found that PN processes are based on relationship-building and instrumental assistance. ${ }^{32,35}$ These findings support the premise that healthcare professionals need to respect patients as individuals whose social circumstances affect their health and health behaviors - a central element of patient-centered care. ${ }^{41,42}$

One limitation of our study was that the PN tracking database only allowed navigators to record time spent in 15-minute intervals, rather than allowing them to add actual time spent, which limited variation needed for some analyses. Additionally, because just more than half ( $55 \%-57 \%$ ) of navigated patients completed the follow-up questions related to satisfaction with $\mathrm{PN}$ and which activities/services were most helpful, this limited our assessments of those constructs. A major strength of this study is its large sample size, particularly compared with similar studies of the PN intervention itself ${ }^{23,26,31}$ and patient satisfaction with PN services. ${ }^{32,35}$ Another strength is this study's use of the data generated by the navigators during the course of their interactions with patients, rather than the report of others either observing or supervising their work. Finally, this study examined 3 important domains: navigator activities, time spent per activity and per patient, and patient satisfaction.

\section{Conclusions}

Although this study pertains to CRC screening via colonoscopy, these findings may inform other cancer screening and treatment programs, including public health programs funded by the CDC that support $\mathrm{PN}$, such as the National Breast and Cervical Cancer Early Detection Program, the CRC Control Program, and the National Comprehensive Cancer Control Program. ${ }^{43}$ Given both the requirement to incorporate $\mathrm{PN}$ services into CoC-accredited cancer programs and the promise patient navigators hold in helping to reduce health disparities, further research of existing $\mathrm{PN}$ programs is needed to refine the nonclinical navigator role to avoid duplicating services already provided, especially by nurses or social workers. ${ }^{18}$ Additionally, future research may explore the relationship between PN services and outcomes, including whether concordance between self-reported barriers and barriers assessed and addressed by navigators influences outcomes.

\section{References}

1. American College of Surgeons Commission on Cancer. Cancer Program Standards 2012: Ensuring Patient-Centered Care. Available at: http://www. facs.org/cancer/coc/programstandards2012.html Accessed February 26, 2012.

2. Freeman HP, Rodriguez RL. History and principles of patient navigation. Cancer 2011;117(Suppl 15):3539-3542.

3. Oncology Nursing Society, the Association of Oncology Social Work, and the National Association of Social Workers Joint Position on the Role of Oncology Nursing and Oncology Social Work in Patient Navigation (adopted March 2010). Available at: http://aosw.org/cms/wp-content/themes/inovado/pdfs/ aosw-public-docs/PR-PositionPatientNav.pdf). Accessed November 5, 2015.

4. Winawer SJ, Zauber AG, Ho MN, et al. Prevention of colorectal cancer by colonoscopic polypectomy. The National Polyp Study Workgroup. N Engl J Med 1993;329:1977-1981.

5. Oluwole SF, Ali AO, Adu A, et al. Impact of a cancer screening program on breast cancer stage at diagnosis in a medically underserved urban community. J Am Coll Surg 2003;196:180-188.

6. Fiscella $\mathrm{K}$, Humiston $\mathrm{S}$, Hendren $\mathrm{S}$, et al. Eliminating disparities in cancer screening and follow-up of abnormal results: what will it take? J Health Care Poor Underserved 2011;22:83-100.

7. Steele $\mathrm{CB}$, Rim SH, Joseph DA, et al. Colorectal cancer incidence and screening-United States, 2008 and 2010. MMWR Suppl 2013;62:53-60.

8. Sabatino SA, White MC, Thompson TD, et al. Cancer screening test use United States, 2013. MMWR Morb Mortal Wkly Rep 2015;64:464-468.

9. Myers RE, Sifri R, Daskalakis C, et al. Increasing colon cancer screening in primary care among African Americans. J Natl Cancer Inst 2014;106:dju344.

10. Ell K, Vourlekis B, Lee PJ, Xie B. Patient navigation and case management following an abnormal mammogram: a randomized clinical trial. Prev Med 2007;44:26-33.

11. Ferrante JM, Chen $\mathrm{PH}, \mathrm{Kim} \mathrm{S}$. The effect of patient navigation on time to diagnosis, anxiety, and satisfaction in urban minority women with abnormal mammograms: a randomized controlled trial. J Urban Health 2008;85:114-124.

12. Jandorf L, Gutierrez Y, Lopez J, et al. Use of a patient navigator to increase colorectal cancer screening in an urban neighborhood health clinic. J Urban Health 2005;82:216-224.

13. Honeycutt S, Green R, Ballard D, et al. Evaluation of a patient navigation program to promote colorectal cancer screening in rural Georgia, USA. Cancer 2013;119:3059-3066.

14. Lasser KE, Murillo J, Lisboa $\mathrm{S}$, et al. Colorectal cancer screening among ethnically diverse, low-income patients: a randomized controlled trial. Arch Intern Med 2011;171:906-912.

15. Lasser KE, Murillo J, Medlin E, et al. A multilevel intervention to promote colorectal cancer screening among community health center patients: results of a pilot study. BMC Fam Pract 2009;10:37.

16. Battaglia TA, Roloff $\mathrm{K}$, Posner MA, Freund KM. Improving follow-up to abnormal breast cancer screening in an urban population. A patient navigation intervention. Cancer 2007;109(2 Suppl):359-367.

17. Grubbs SS, Polite BN, Carney J Jr, et al. Eliminating racial disparities in colorectal cancer in the real world: it took a village. J Clin Oncol 2013;31:19281930.

18. Willis A, Reed E, Pratt-Chapman M, et al. Development of a framework for patient navigation: delineating roles across navigator types. J Oncol Navig Surviv 2013;4:20-26. 
Rohan et al

19. Jandorf L, Cooperman JL, Stossel LM, et al. Implementation of culturally targeted patient navigation system for screening colonoscopy in a direct referral system. Health Educ Res 2013;28:803-815.

20. Steinberg ML, Fremont A, Khan DC, et al. Lay patient navigator program implementation for equal access to cancer care and clinical trials: essential steps and initial challenges. Cancer 2006;107:2669-2677.

21. Percac-Lima S, Grant RW, Green AR, et al. A culturally tailored navigator program for colorectal cancer screening in a community health center: a randomized, controlled trial. J Gen Intern Med 2009;24:211-217.

22. Percac-Lima S, Lopez L, Ashburner JM, et al. The longitudinal impact of patient navigation on equity in colorectal cancer screening in a large primary care network. Cancer 2014;120:2025-2031.

23. Lin $\mathrm{C}$, Schwaderer $\mathrm{K}$, Morgenlander $\mathrm{K}$, et al. Factors associated with patient navigators' time spent on reducing barriers to cancer treatment. J Natl Med Assoc 2008;100:1290-1297.

24. Vargas RB, Ryan GW, Jackson CA, et al. Characteristics of the original patient navigation programs to reduce disparities in the diagnosis and treatment of breast cancer. Cancer 2008;113:426-433.

25. Ramsey S, Schneider J; The Association of State and Territorial Health Officials. Improving Cancer Prevention and Control: How State Health Agencies Can Support Patient Navigators and Community Health Workers. Available at: http://www.astho.org/ImprovingCancerPreventionandControl/. Accessed October 12, 2016.

26. Dohan D, Schrag D. Using navigators to improve care of underserved patients. Cancer 2005; 104:848-855

27. Wells KJ, Luque JS, Miladinovic B, et al. Do community health worker interventions improve rates of screening mammography in the United States? A systematic review. Cancer Epidemiol Biomarkers Prev 2011;20:1580-1598.

28. Wells $\mathrm{KJ}$, Meade $\mathrm{CD}$, Calcano $\mathrm{E}$, et al. Innovative approaches to reducing cancer health disparities. J Cancer Educ 2011;26:649-657.

29. Wells KJ, Battaglia TA, Dudley DJ, et al. Patient navigation: state of the art or is it science? Cancer 2008;113:1999-2010.

30. Community Preventive Services Task Force. Updated Reviews and Findings added to The Community Guide: Increasing breast, cervical, \& colorectal cancer screening. The Community Guide 2012. Available at: http://www. thecommunityguide.org/news/2012/CancerClientOrientedUpdate.html. Accessed November 18, 2015.

31. Parker VA, Clark JA, Leyson J, et al. Patient navigation: development of a protocol for describing what navigators do. Health Serv Res 2010;45:514-531.

\section{Instructions for Completion}

To participate in this journal CE activity: 1) review the learning objectives and author disclosures; 2 ) study the education content; 3) take the posttest with a $66 \%$ minimum passing score and complete the evaluation at http://education.nccn.org/ node/79763; and 4) view/print certificate. After reading the article, you should be able to answer the following multiple-
32. Jean-Pierre P, Hendren S, Fiscella K, et al. Understanding the processes of patient navigation to reduce disparities in cancer care: perspectives of trained navigators from the field. Journal of Cancer Educ 2011;26:111-120.

33. Escoffery C, Fernandez ME, Vernon SW, et al. Patient navigation in a colorectal cancer screening program. J Public Health Manag Pract 2015;21:433-440.

34. Gunn CM, Clark JA, Battaglia TA, et al. An assessment of patient navigator activities in breast cancer patient navigation programs using a nine-principle framework. Health Serv Res 2014;49:1555-1577.

35. Carroll JK, Humiston SG, Meldrum SC, et al. Patients' experiences with navigation for cancer care. Patient Educ Couns 2010;80:241-247.

36. Campbell C, Craig J, Eggert J, Bailey-Dorton C. Implementing and measuring the impact of patient navigation at a comprehensive community cancer center Oncol Nurs Forum 2010;37:61-68.

37. Jean-Pierre P, Fiscella K, Freund KM, et al. Structural and reliability analysis of a patient satisfaction with cancer-related care measure: a multisite patient navigation research program study. Cancer 2011;117:854-861.

38. The 189th General Court of Commonwealth of Massachusetts. Session Law: An Act Providing Access to Affordable, Quality, Accountable Health Care. Available at: http://www.mass.gov/legis/laws/seslaw06/s1060058.htm. Accessed October 12, 2016

39. Ward E, Jemal A, Cokkinides V, et al. Cancer disparities by race/ethnicity and socioeconomic status. CA Cancer J Clin 2004;54:78-93.

40. Freund KM, Battaglia TA, Calhoun E, et al. Impact of patient navigation on timely cancer care: the Patient Navigation Research Program. J Natl Cancer Inst 2014;106:dju115.

41. Institute of Medicine Committee on Quality of Health Care in America. Crossing the Quality Chasm: A New Health System for the 21st Century. National Academy Press: Washington, DC; 2001. Available at: https://www. nap.edu/read/10027/chapter/1. Accessed October 12, 2016.

42. Epstein RM, Street RL. The values and value of patient-centered care. Ann Fam Med 2011;9:100-103.

43. Centers for Disease Control and Prevention. Cancer Prevention and Control: Foundational Programs. Available at: http://www.cdc.gov/cancer/dcpc/about/ programs.htm). Accessed October 12, 2016

\section{See JNCCN.org for supplemental online content.}

\section{Posttest Questions}

1. True or False: Oncology PN is a process that provides individualized assistance to patients, families, and caregivers to help overcome healthcare system barriers and facilitate timely access to quality health and psychosocial care from prediagnosis through all phases of the cancer experience.

2. In this study, the most commonly reported barrier to colonoscopy screening for the participants was

a. Time off work

b. Transportation

c. Out-of-pocket expenses

d. Elder or child care

e. Lack of education about the colonoscopy procedure choice questions. Credit cannot be obtained for tests completed on paper. You must be a registered user on NCCN.org. If you are not registered on NCCN.org, click on "New Member? Sign up here" link on the left hand side of the Web site to register. Only one answer is correct for each question. Once you successfully answer all posttest questions you will be able to view and/or print your certificate. Software requirements: Internet f. A need for language translation

g. Scheduling the appointment

3. In this study, the navigator interventions that patients identified as most helpful were the provision(s) of

a. Encouragement/social support

b. An explanation of the colonoscopy procedure and bowel prep

c. Education about the importance of completing the colonoscopy

d. Transportation or escort after the procedure

e. Appointment scheduling

f. Language concordance between patient and navigator

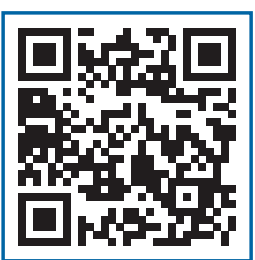

November 2016 


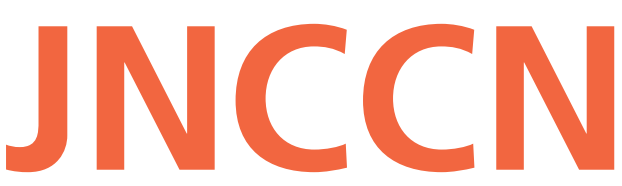

Journal of the National Comprehensive Cancer Network

Supplemental online content for:

\section{Refining the Patient Navigation Role in a Colorectal Cancer Screening Program: Results From an Intervention Study}

Elizabeth A. Rohan, PhD, MSW; Beth Slotman, MS; Amy DeGroff, PhD, MPH;

Kerry Grace Morrissey, MPH; Jennifer Murillo, BA; and Paul Schroy, MD, MPH

J Natl Compr Canc Netw 2016;14(11):1371-1378

- eAppendix 1: Screenshots of PN Colonoscopy Tracking Form 


\section{eAppendix 1. Screenshots of PN Colonoscopy Tracking Form}

Many of these fields will be pre-populated but the patient navigator should review and verify at initial encounter.

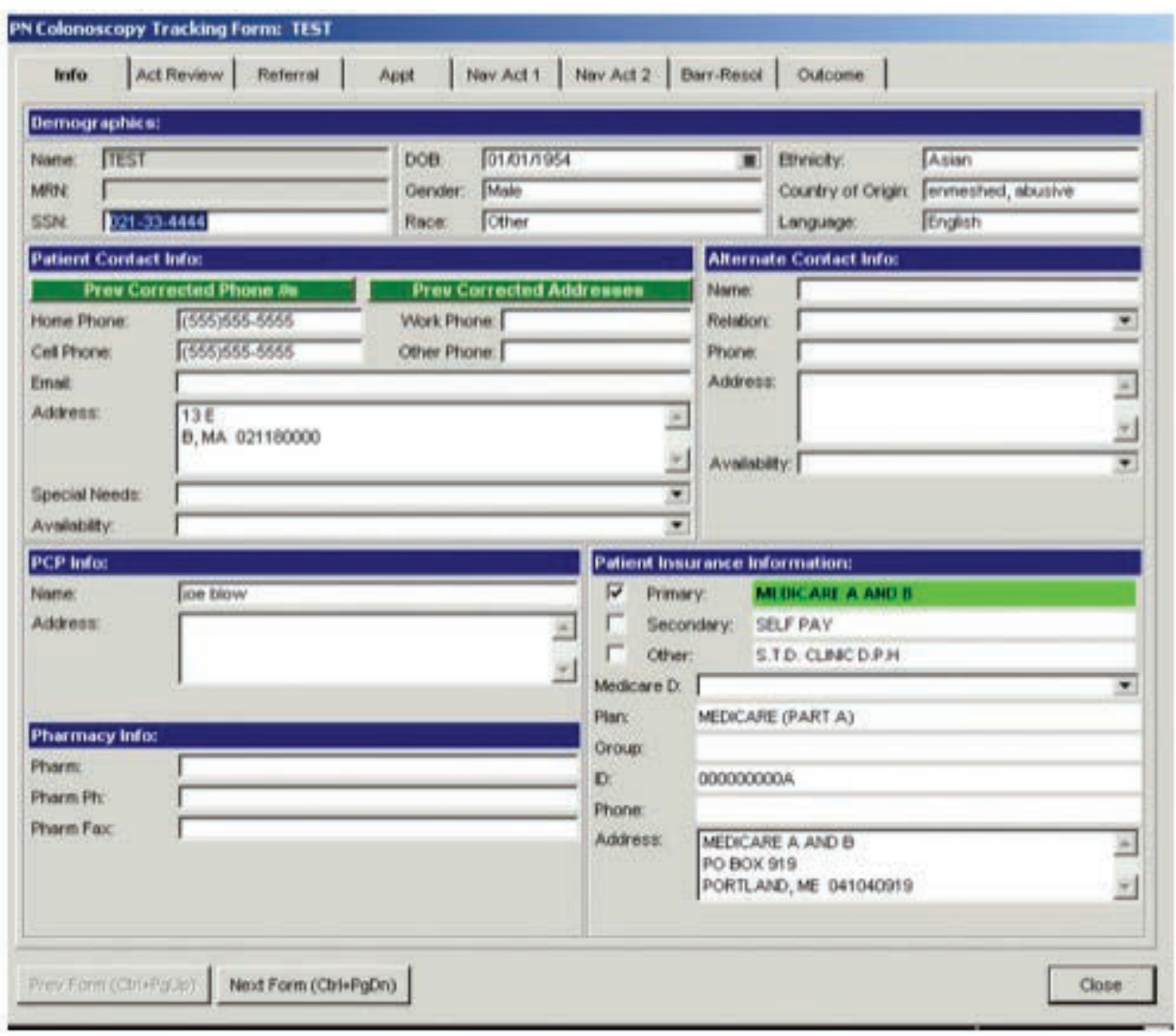

Form 1: A new note with be created for each encounter with the navigator. Previously entered information will appear, but only newly added or edited information appears in the actual electronic medical record note; all fields are searchable. 
eAppendix 1. Screenshots of PN Colonoscopy Tracking Form (cont.)

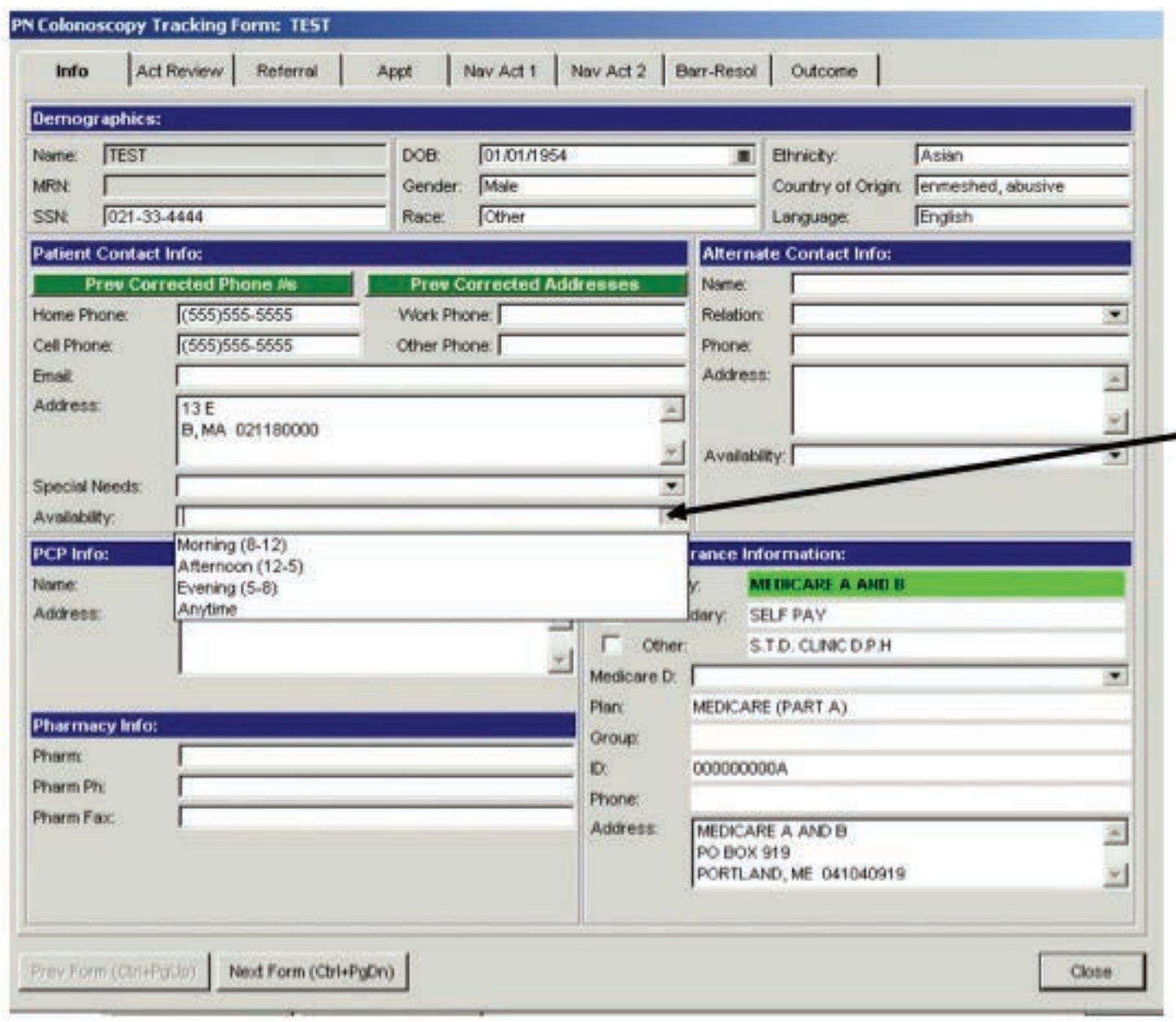

Data entry fields with drop-down menus also allow flexibility to insert text if needed for free-texting if needed. 
eAppendix 1. Screenshots of PN Colonoscopy Tracking Form (cont.)

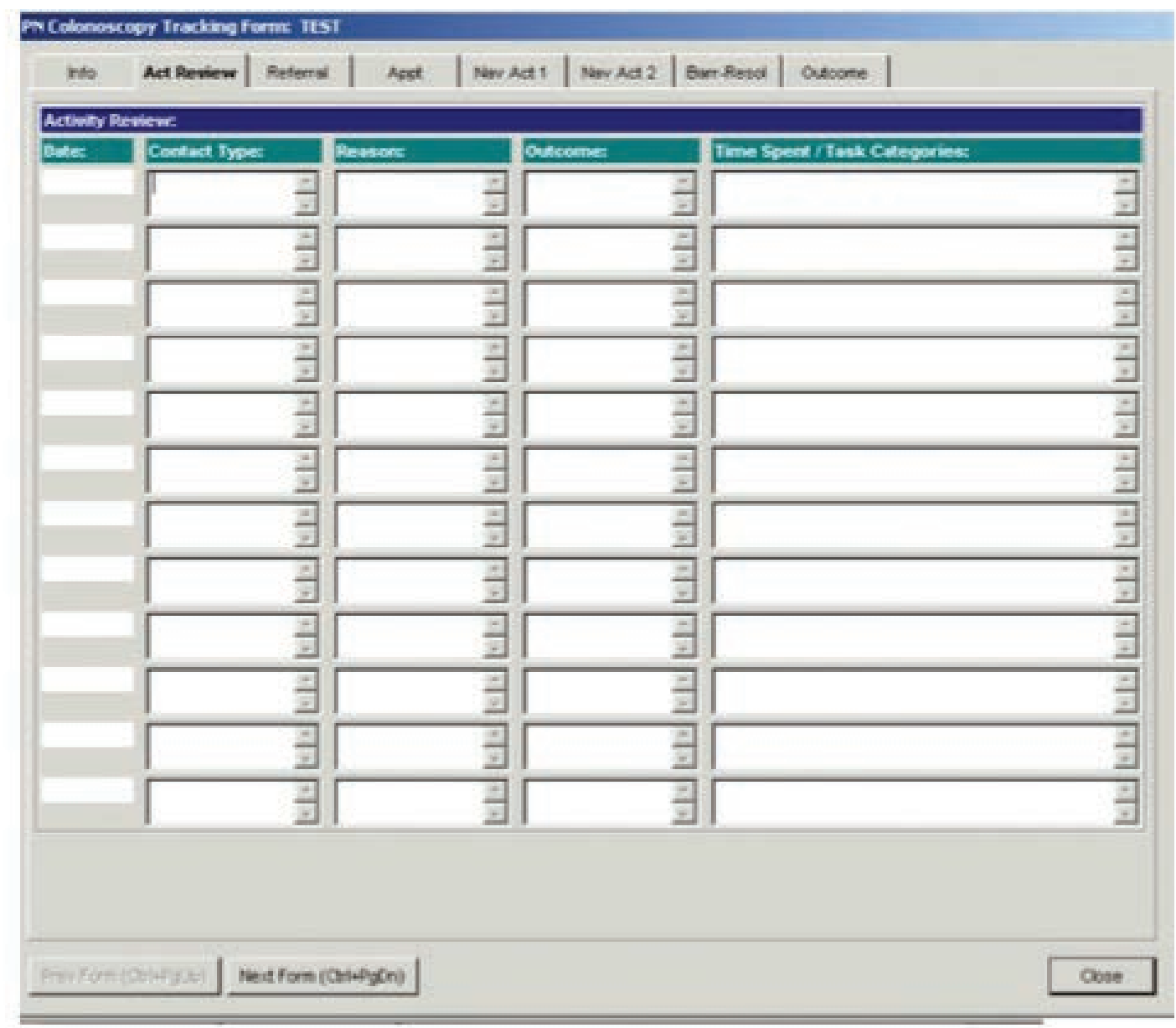

Form 2: This form summarizes patient-specific information from previous encounters with the navigator. 
eAppendix 1. Screenshots of PN Colonoscopy Tracking Form (cont.)

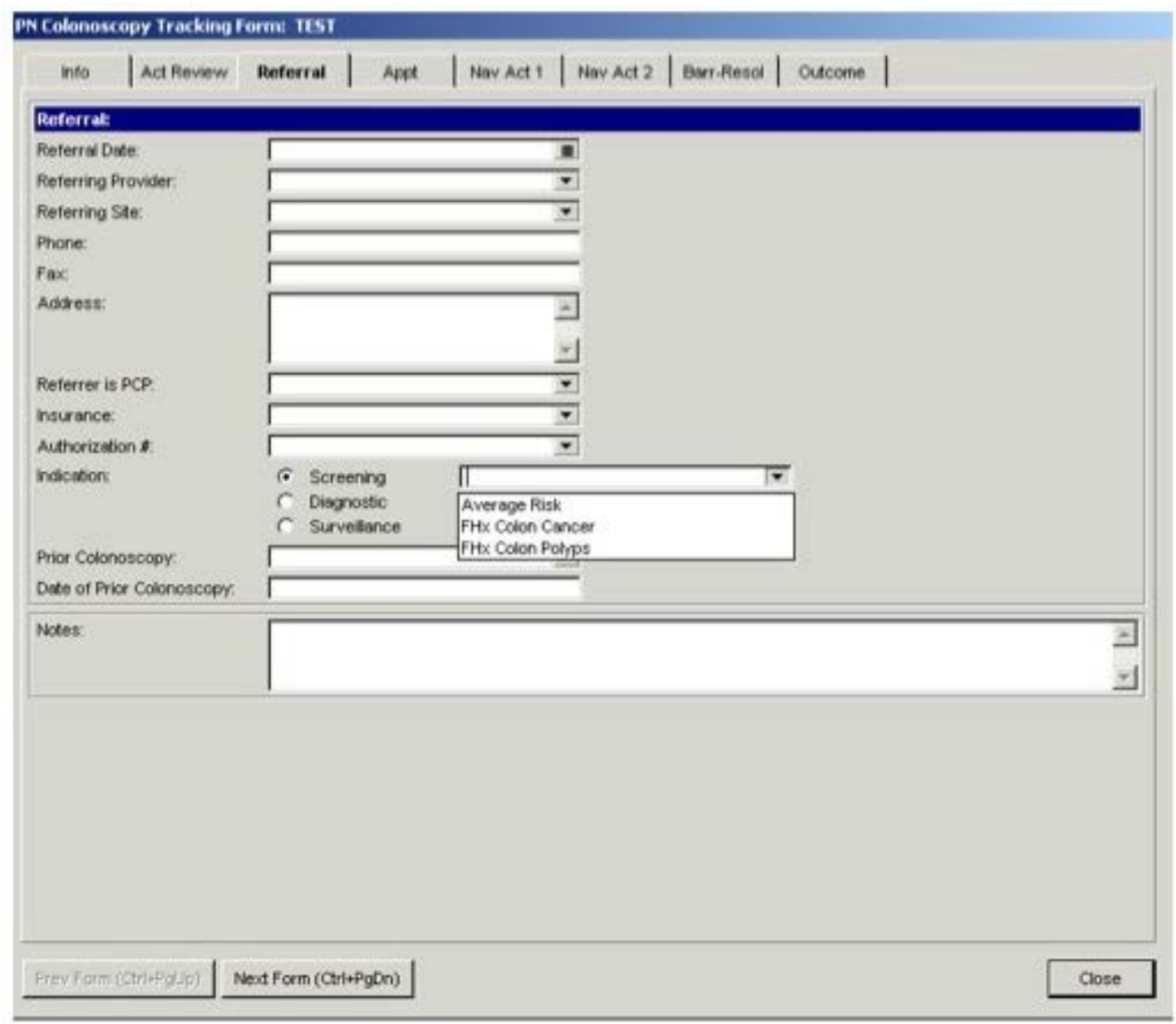

Form 3: Here the patient navigator (and research coordinator for control patients) should document date the colonoscopy referral was generated (which should be date of enrollment), referring provider, and indication at a minimum. 


\section{eAppendix 1. Screenshots of PN Colonoscopy Tracking Form (cont.)}
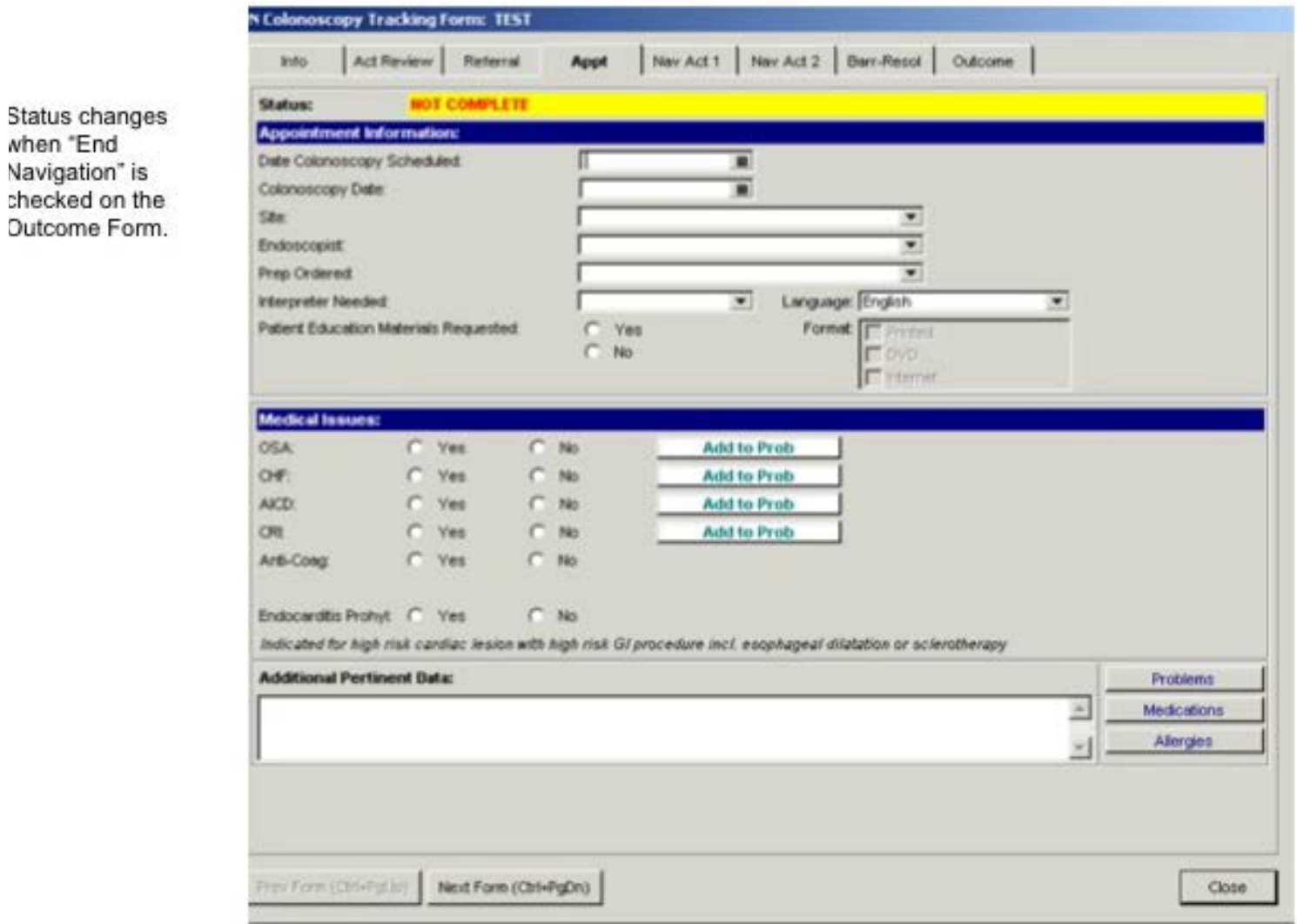

Form 4: Here the patient navigator (and research coordinator for control patients) will add the date the colonoscopy was actually scheduled (this should be the same date as enrollment and referral date initially, but could change if the patient reschedules), the appointment date, endoscopist, preparation ordered (from drop-down menu), need for interpreter and whether the patient has requested education materials. The "Medical Issues" section is derived from the referral from and helps identify which patients may need some form of medical clearance with one of the triage nurses or anesthesiologists. 


\section{eAppendix 1. Screenshots of PN Colonoscopy Tracking Form (cont.)}

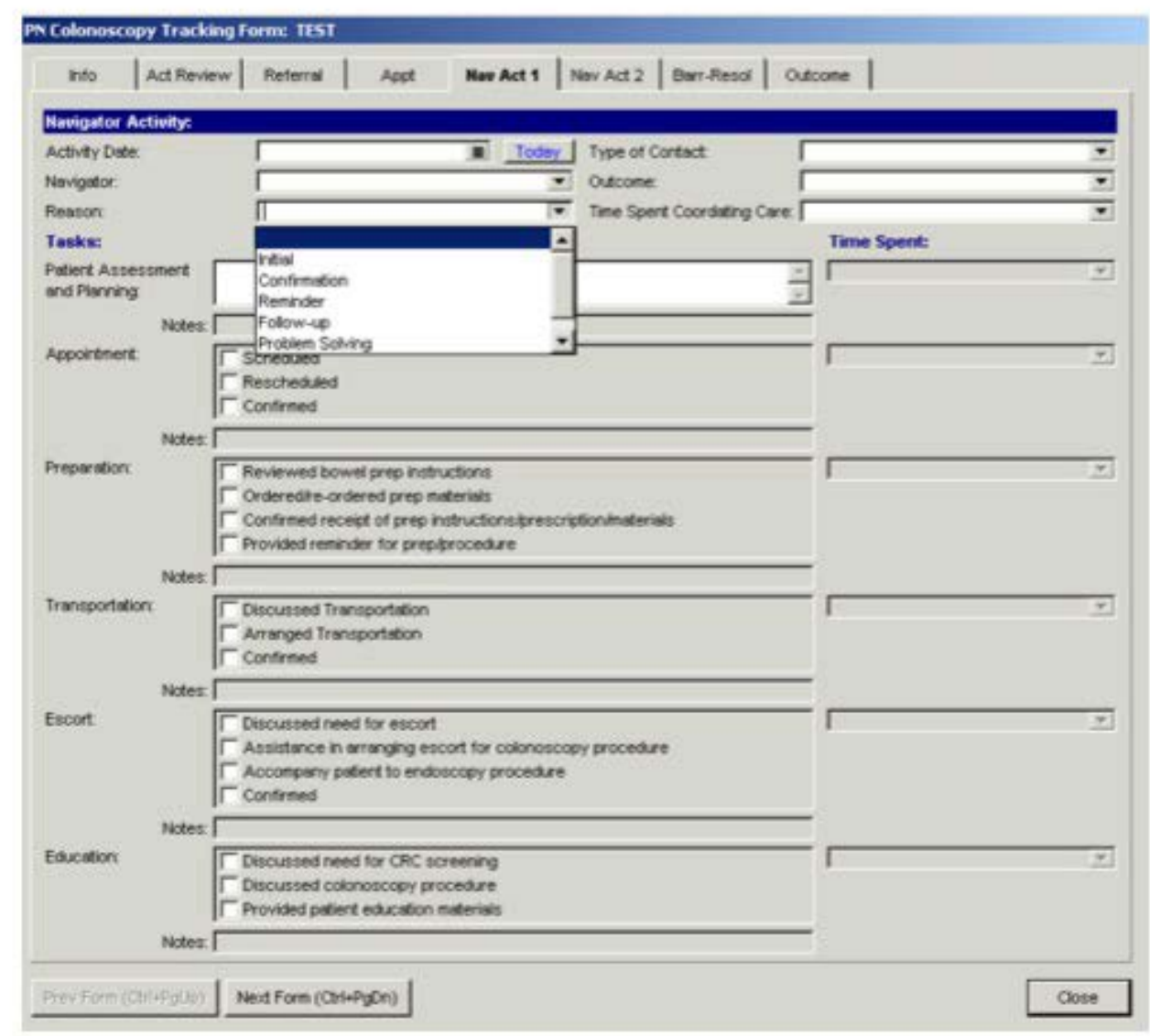

Form 5: Here the patient navigator documents the reason for an interaction (see drop-down list), type of contact (eg, "phone" or "in person"), outcome (eg, "contacted", "left message", etc.), and time spent, as well as specific activities performed with time spent (eg, <15 min, 15-30 min, etc.). 
eAppendix 1. Screenshots of PN Colonoscopy Tracking Form (cont.)

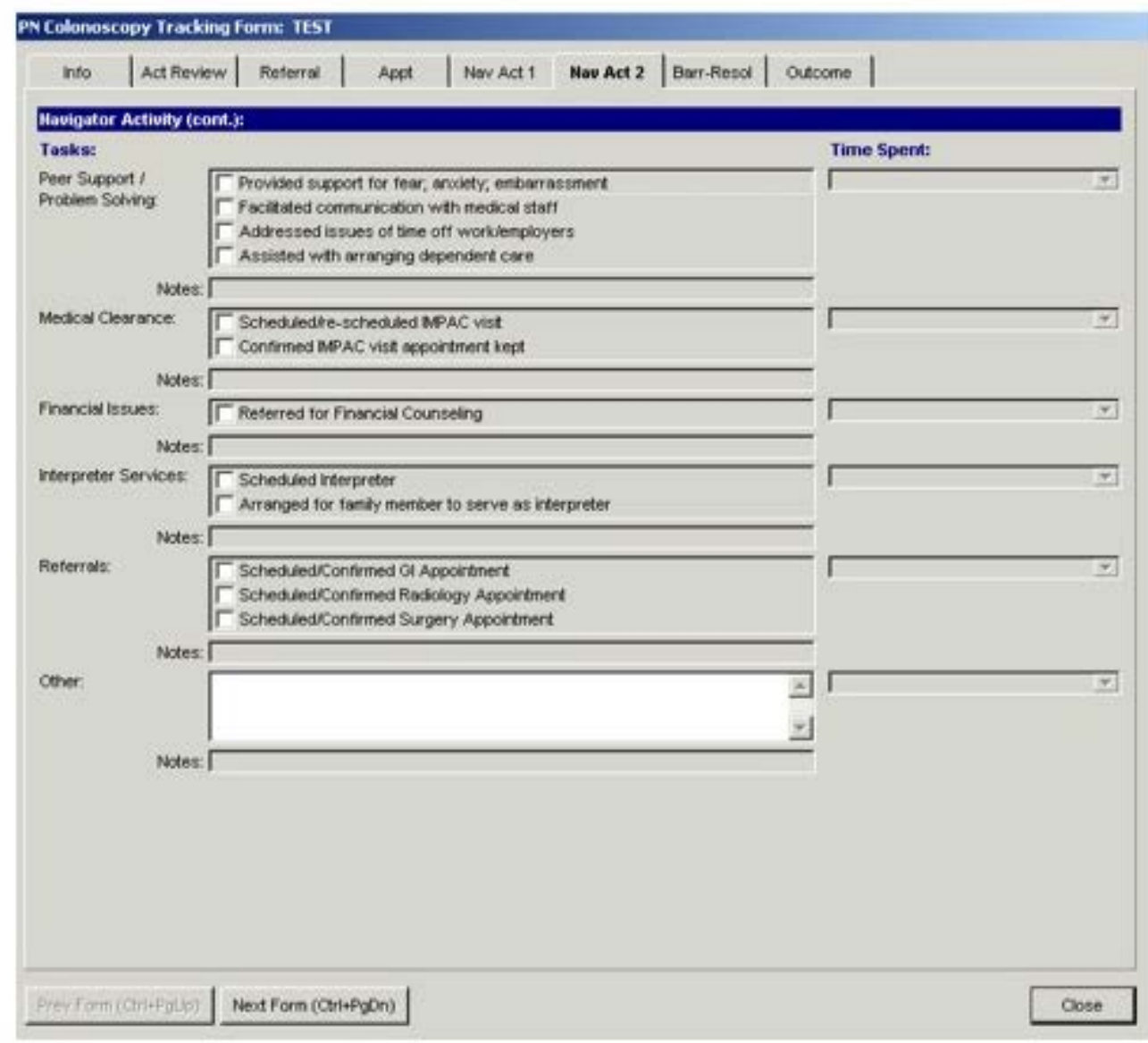

Form 6: This is a continuation of Form 5 with additional possible activities. 
eAppendix 1. Screenshots of PN Colonoscopy Tracking Form (cont.)

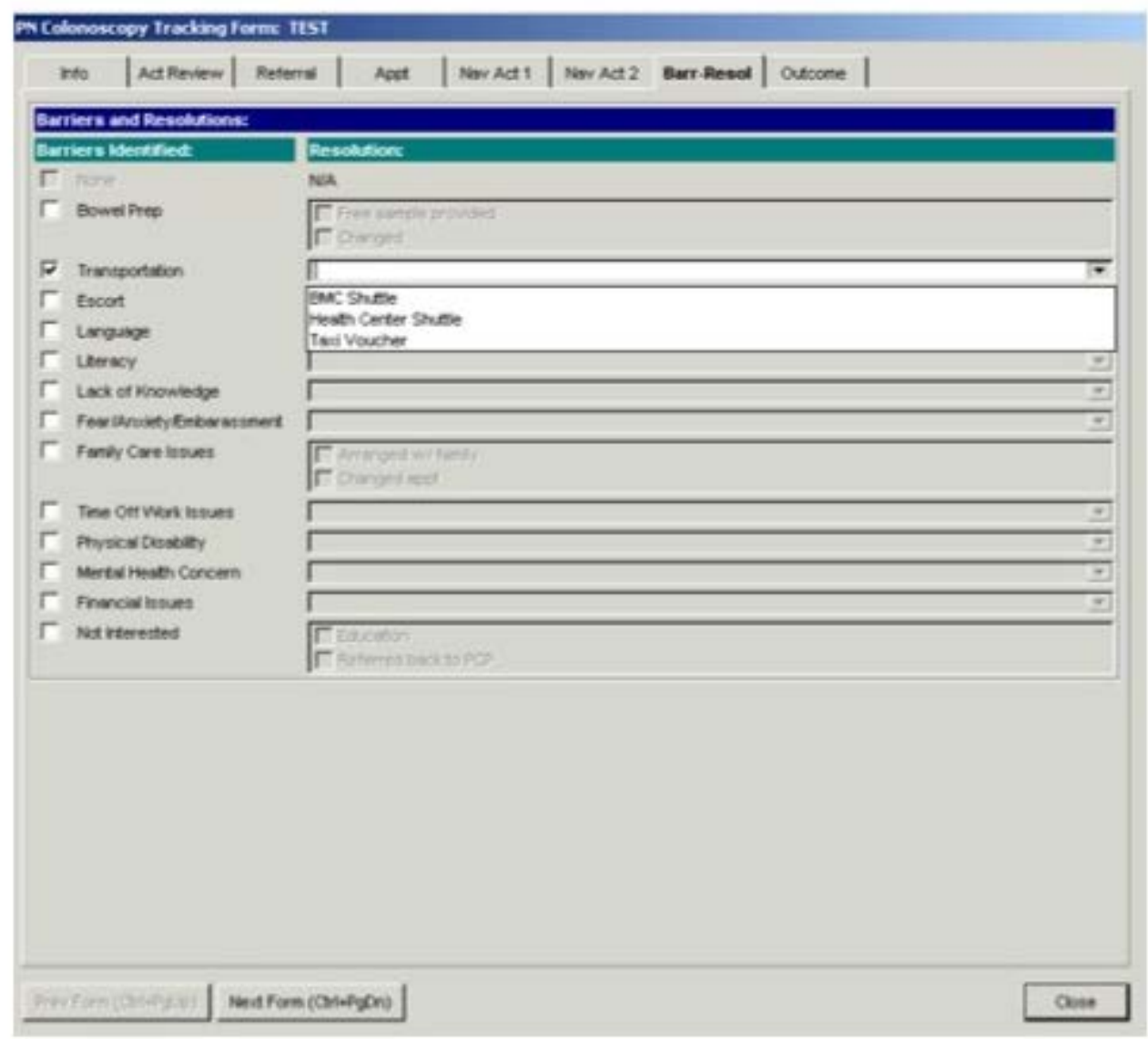

Form 7: List of potential barriers and resolutions with a check box or drop-down menu list of options (as per Transportation example). The patient navigator can also add free text. 


\section{eAppendix 1. Screenshots of PN Colonoscopy Tracking Form (cont.)}

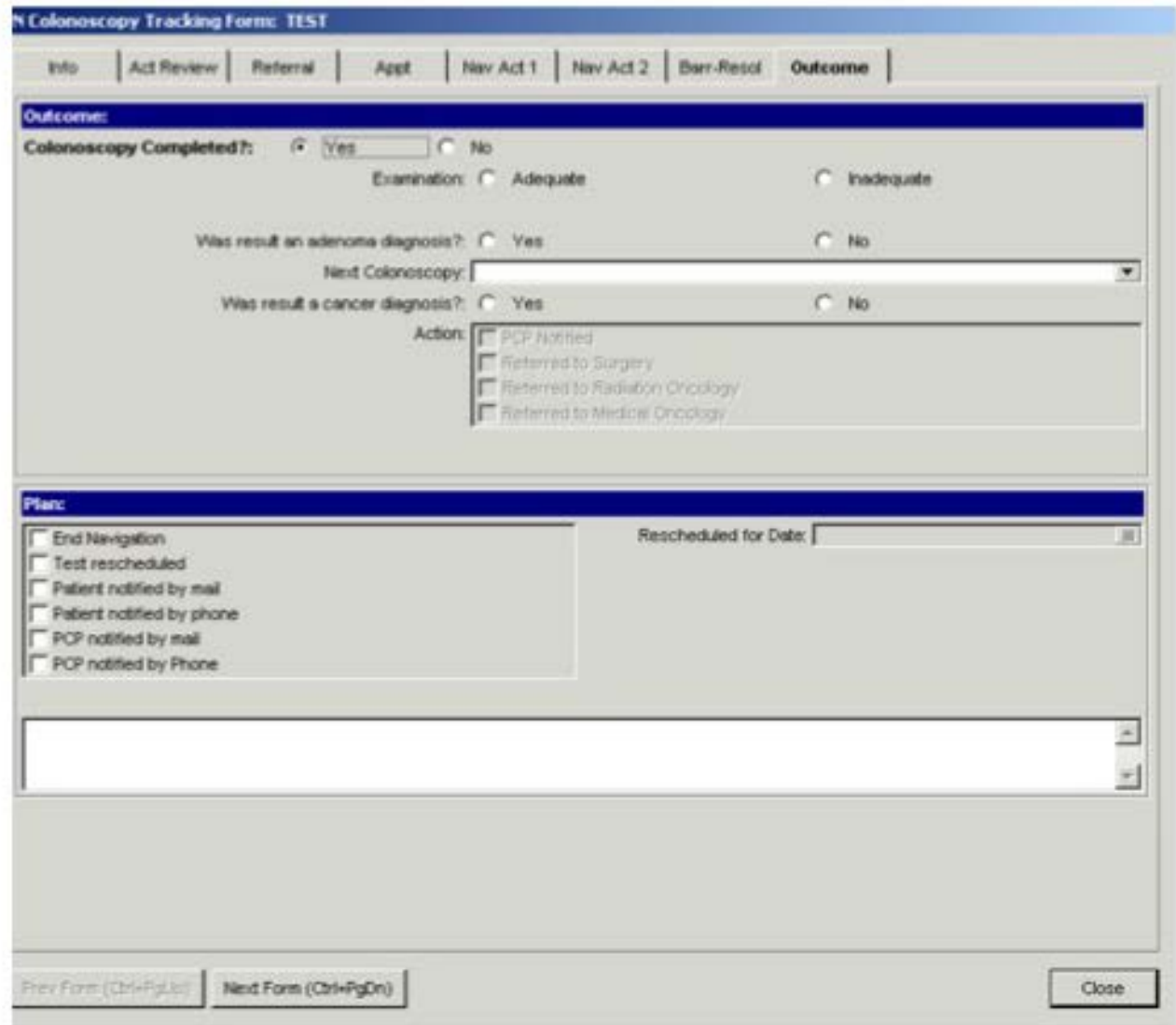

Form 8: Outcome form will appear if 'Yes' is checked next to "Colonoscopy Completed"; the drop-down menu will appear if "Inadequate" is checked with options such as "poor prep" or "patient tolerance". The adenoma or cancer diagnosis fields will not be used for tracking outcomes in this study, but rather for future internal use related to recall for surveillance. 


\section{eAppendix 1. Screenshots of PN Colonoscopy Tracking Form (cont.)}

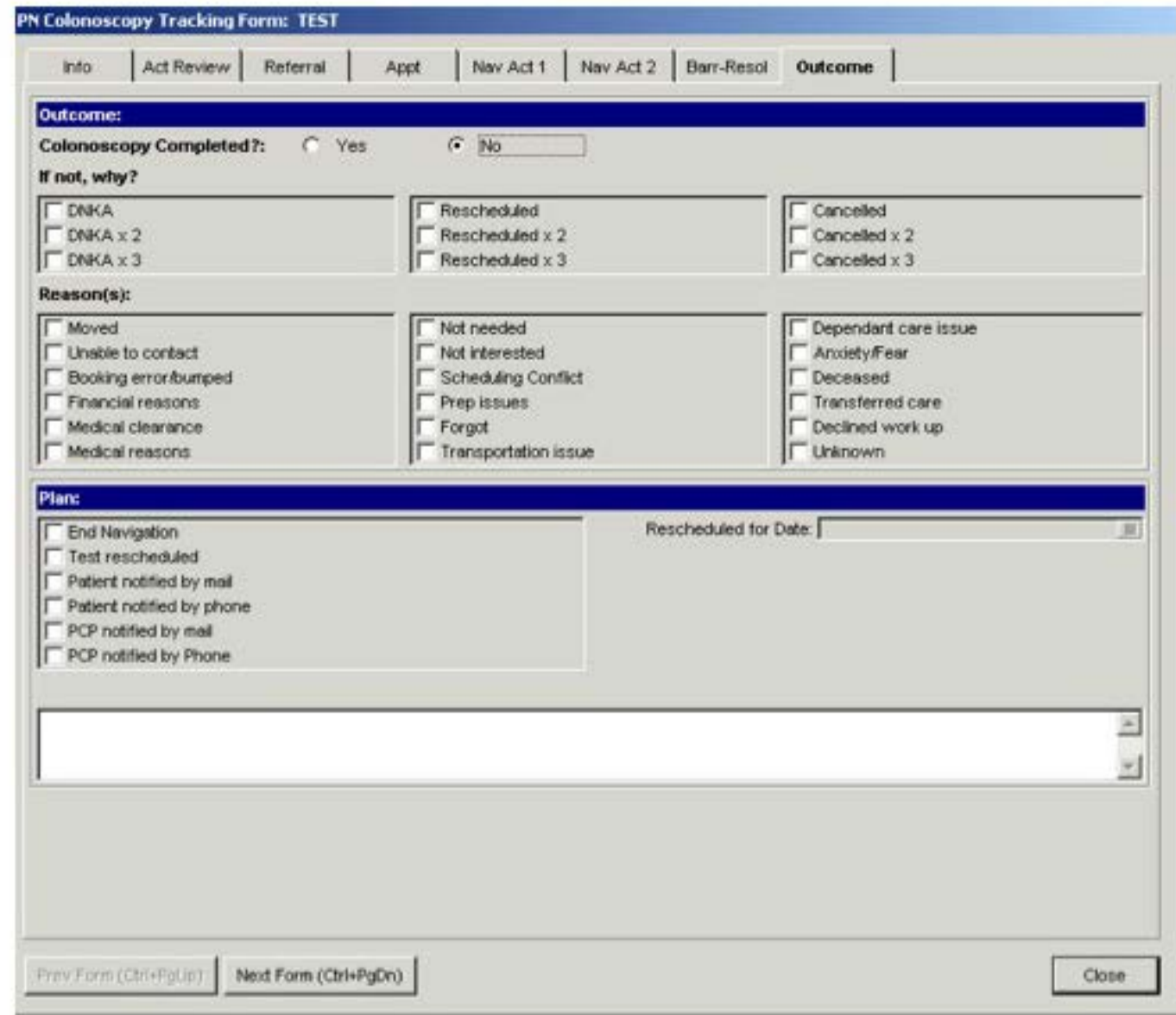

Form 8 (cont.): Outcome form if "No" is checked next to "Colonoscopy Completed". For "Test Rescheduled" checked under "Plan", the appointment date will reset on Form 4. 